\title{
The Effect of Abdominal-Compression Belt on Balance Ability with One Leg Standing
}

\author{
Ki-Yeon Chang ${ }^{1}$, Seung-Chul Chon ${ }^{2}$ \\ ${ }^{1}$ Department of Occupational therapy, The University of Woosong, Daejeon, 300-718 \\ ${ }^{2}$ Department of Physical therapy, The University of Konyang, Daejeon, 302-718
}

\begin{abstract}
Objective: The aim of this study was to determine the effect of abdominal-compression belt in one leg standing on balance in normal adult. Background: With the effects of increased intra-abdominal pressure, the abdominal-compression belt is contributing to a static balance control. However, specific study is still insufficient. Method: Forty subjects were randomly allocated to two groups: control $(\mathrm{n}=20)$ and experimental group $(\mathrm{n}=20)$, respectively. The experimental group used an abdominal-compression belt, whereas the control group did not that. All subjects were educated using pressure biofeedback unit and ultrasound imaging for exact application by abdominal-compression belt. Main outcome measurement was used a general stability index, fourier harmony index, weight distribution index, and fall index in tetrax balance system. Results: Experimental group improved significantly on general stability, only 2 factors(eyes closed with head turned forward and eyes closed with head turned backward) among fourier harmony index, and fall index, However, weight distribution index did not revealed significant difference. Conclusion: The findings suggest that application of abdominal-compression belt could be effective on improving balance ability in one leg standing of normal adults. Application: The results of the abdominal-compression belt might help to control balance in workers.
\end{abstract}

Keywords: Tetrax, Balance, One leg standing, Ultrasound, Abdominal-compression belt

\section{Introduction}

균형은 기저면(base of support) 위에서 중력중심(center of gravity)을 유지하는 능력으로 산업체 근로자의 현장 및 기능적인 일상생활동작 수행 시에 중요한 역할을 담당한다 (Kisner and Colby, 2007; Oude Hengel et al., 2010). 균 형능력은 시각, 고유수용성감각 및 전정감각이 통합된 감각 조직화(sensory organization) 과정으로 안정성과 운동성을 동시에 필요로 하는 신경근골격계의 감각입력, 운동감각통합 및 운동실행의 과정을 통하여 체간 심부근육의 안정화 능력 을 필요로 하게 된다(Kisner and Colby, 2007).
안정화 운동은 복부 심부근육을 강화시키는 운동으로, 척 추 및 관련 조직에 안정성을 제공함으로써 신경근골격계의 운동실행력을 증가시킨다(Akuthota and Nadler, 2004). Hodges (2003)는 체간 심부근육인 복횡근 및 다열근에 압 박을 가하는 하복부의 동시수축이 체간 안정성을 증가시킨다 고 하였고, 선택적인 하복부 복횡근 수축은 복부내압(intraabdominal pressure) 과 요천추 근막(thoracolumbar fascia) 의 긴장감을 증가시켜 척추부하 (spinal load)를 감소시킨 다고 하였다. 이러한 선택적인 하복부 수축력 증가는 안 정화 운동 훈련 중 가장 효과적인 방법으로 보고되고 있다 (Akuthota and Nadler, 2004).

하복부 수축은 척추 불안정(lumbar instability)으로 인한

Corresponding Author: Seung-Chul Chon. Department of Physical therapy, The University of Konyang, Daejeon, $302-718$.

Phone: 042-600-6327, E-mail: keyjune@konyang.ac.kr

Copyright@2012 by Ergonomics Society of Korea(pISSN:1229-1684 eISSN:2093-8462). All right reserved.

(c) This is an open-access article distributed under the terms of the Creative Commons Attribution Non-Commercial License(http://creativecommons.org/licenses/by-nc/3.0/), which permits unrestricted non-commercial use, distribution, and reproduction in any medium, provided the original work is properly cited. 
자세 불안정성 (postural instability)을 해결함으로써 균형조 절에 도움을 준다(Akuthota and Nadler, 2004). Cynn 등 (2006)은 압력 피드백 (pressure biofeedback unit; PBU) 장비를 이용한 안정화 운동이 균형조절에 필요한 고관절 외 전근 수행 시에 골반조절에 더 효과적이라고 하였고, Lee (2010)는 안정화 훈련이 정상인의 한발 서기 균형능력 향 상에 도움을 준다고 하였고, Willson 등(2005)은 척추 안정 화 운동이 보행에 필요한 하지(lower extremity)의 기능 향상과 비례한다고 하였고, Kim 등(2003)은 슬링을 이용한 안정화 훈련이 균형능력에 효과적이라고 하였다.

압박벨트는 하복부와 요천추 후면을 비탄력성 밴드로 감 싸듯이 고정시키는 것으로써, 하복부 내압, 요천추 근막의 긴장감 및 천장관절(sacroiliac joint)의 안정성을 강화시켜 척추 안정화에 도움을 준다고 하였다(Pel et al., 2008). 특 히, 천장관절은 균형능력에 필요한 하지근육과 복부근육들 이 부착되는 곳으로(Pel et al., 2008), 힘 잠김 기전(force closure mechanism)을 통하여 하복부와 골반을 동시에 안 정화시킬 수 있다고 하였다(Damen et al., 2001). Damen 등(2001)은 정상적인 여성을 대상으로 압박벨트를 적용한 결과 천장관절의 느슨함을 보완할 수 있다고 하였고, Mens 등(2006)은 임신중인 여성을 대상으로 골반압박벨트를 적 용하여 운동기능이 향상된 이유로 복부압력의 증가를 보고 하였다. 또한, 복부압박벨트는 일상생활동작 중에도 지속적 으로 척추 안정화 효과를 볼 수 있는 장점을 가지고 있다. 이러한 복부압박벨트의 간편성과 기능성에도 불구하고 직접 적인 균형능력과 관련된 연구는 매우 한정적이다.

균형능력을 측정할 수 있는 객관적인 장비로 균형 측정기 는 근골격계 질환자의 균형능력 측정에 용이하며, 체중 분포 도, 낙상 지수, 전정기관 및 균형조절에 필요한 중추신경계 요인까지 측정이 가능하다(Kim et al., 2009). 이러한 장점 에도 불구하고 대부분의 연구는 정적인 상태에서 낙상 지수 를 평가한 연구가 대부분이다. 따라서 본 연구에서는 일상생 활동작 중에 지속적으로 안정화 효과를 유도할 수 있는 복부 압박벨트를 착용하여 한발 서기 자세에서 균형 측정기를 이 용하여 구체적인 균형능력에 미치는 영향을 알아보고자 하 였다.

\section{Method}

\subsection{Subjects}

본 연구는 건강한 정상 성인 40 명 (실험군 20 명, 대조군 20명)을 대전소재 대학에서 편의적으로 추출하였다. 연구에 참가하기 전 대상자에게 연구목적과 실험방법에 대하여 충
분히 설명한 후 실험동의서를 얻었다. 연구대상자 선정조건 은 양하지 체중분배에 영향을 주는 신체적 결함이 없고, 최 근 6 개월간 요통을 경험하지 않았고, 균형유지를 위해 시각, 청각 및 고유수용성감각에 결손이 없는 건강한 성인으로 하 였다. 그리고 시각 장애가 있는 자, 전정기관 장애나 신경학 적 장애로 진단받은 자, 근골격계 장애가 있는 자, 정신적인 장애가 있는 자, 실험 24시간 내에 알코올을 섭취한 자, 최 근 1 개월 내 낙상 경험이 있는 자, 한발 서기 자세를 1 분 이 상 유지할 수 없는 자는 대상자에서 제외하였다(Table 1).

Table 1. General characteristics of subjects $(\mathrm{N}=40)$

\begin{tabular}{l|c|c|c|c}
\hline Characteristics & Experimental & Control & $\mathrm{t}$ & $p$ \\
\hline Age $(\mathrm{yrs})$ & $23.70 \pm 4.12$ & $23.00 \pm 1.84$ & .694 & .492 \\
\hline Weight $(\mathrm{kg})$ & $63.92 \pm 12.99$ & $61.66 \pm 12.10$ & .568 & .573 \\
\hline Height $(\mathrm{cm})$ & $168.35 \pm 6.52$ & $166.85 \pm 9.80$ & .570 & .572 \\
\hline
\end{tabular}

\subsection{Equipment used}

균형능력을 측정하기 위하여 균형 측정기 (Tetrax balance system, Sunlight Inc., Israel)를 사용하였다. 균형 측정기 는 4 개로 구성된 발판에 대상자의 양쪽 발뒤꿈치와 발전면 부를 각각 위치시키고 측정하는 장비로, 본 연구에서는 가로 $30 \mathrm{~cm}$, 세로 $30 \mathrm{~cm}$ 및 높이 $3.5 \mathrm{~cm}$ 크기로 발판 4 개의 중앙 부위에 제작한 목판이 정확히 위치할 수 있도록 4 개의 미끄 럼 방지 패드를 각각 부착시켜 제작하였다(Figure 1). 미끄 럼 방지 패드는 균형 측정기 발판 규격에 맞춰 한발 서기 자 세에서 체중이 고르게 분포되도록 부착시켰고, 목판 정중앙 부위에 한발을 위치시킬 수 있도록 펜으로 표시하였다. 균형 측정은 외부 자극이 없는 조용한 방에서 시행되었으며, 대상 자는 맨발로 우측 발을 펜으로 표시한 발판 정중앙에 위치시 키고, 편안하게 선 자세에서 균형이 고르게 분포하는지 확인 후 측정을 시작하였다.

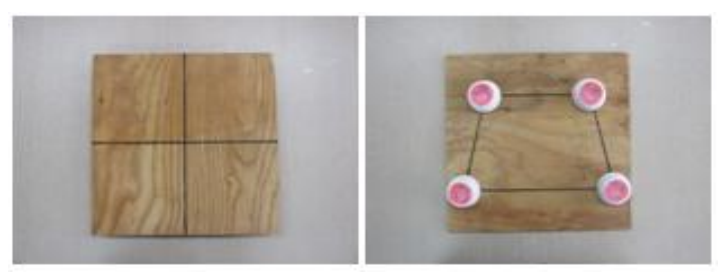

Figure 1. Foot plate for one leg standing

Left: Above of foot plate Right: Below of foot plate

균형 측정기는 눈 뜨고 머리 정위하여 서기(Normal 
position with eyes open, solid surface; NO), 눈 감고 머 리 정위하여 서기(Normal position with eyes closed; NC), 쿠션 위에 올라가 눈 뜨고 머리 정위하여 서기(Eyes open with on pillows; PO), 쿠션 위에 올라가 눈 감고 머리 정위 하여 서기 (Eyes closed with on pillow; PC), 눈감고 머리 오른쪽으로 돌리기(Eyes closed with head turned right; $\mathrm{HR}$ ), 눈감고 머리 왼쪽으로 돌리기(Eyes closed with head turned left; HL), 눈감고 머리 위로 들기(Eyes closed with head turned forward; HF) 및 눈감고 머리 오른쪽으로 돌 리기 (Eyes closed with head turned backward; HB) 로 구 성된 총 8 개 자세에서 시행되었으며, 각 자세에서의 검사시 간은 약 40 초 소요되었다. 8 개 자세에서 측정된 균형능력은 안정성 지수, 퓨리에 지수, 체중분포 지수 및 낙상 지수 4 가 지로 나누어 분석하였다.

\subsubsection{General stability index; GST}

안정성 지수는 4 개 발판에서 자세동요 정도를 측정하여 전반적인 안정성을 나타내는 수치로, 대상자의 자세변화 조 절과 보상능력을 평가한다. 안전성 지수는 총 0 100점으로, 낮을수록 안정된 균형능력을 의미한다(Kohen-Raz, 1991).

\subsubsection{Fourier harmony index; FHI}

퓨리에 지수는 자세동요의 강도를 회귀분석한 내용으로, 병변 부위에 따라 다른 진동수를 나타낸다. 이는 자세조절를 위한 시각, 전정감각 및 고유수용성감각과 중추신경계 기 능의 통합 과정을 반영하는 점수이다. 정상은 .90 .99점이 고, .70점 이하면 균형에 문제가 있음을 나타낸다( $\mathrm{Kim}$ 등, 2009).

\subsubsection{Weight distribution index; WDI}

체중분포 지수는 4 개 발판에 분배되는 체중의 분포 정도 를 퍼센트로 각각의 4 개 발판은 $25 \%$ 에 해당된다. 체중분포 지수는 점수로 표시되어 0 점에 가까울수록 자세가 경직되어 있음을 나타내고, 4 6점은 정상 그리고 6점 이상은 체중분 배 능력이 저하되었음을 의미한다(Kohen-Raz, 1991).

\subsubsection{Fall index; FI}

낙상 지수는 낙상에 영향을 줄 수 있는 안정성 지수, 퓨리 에 지수 및 체중분포 지수가 통합되어 낙상 위험도를 나타낸 다. 0 35점은 최소한의 위험, 36 57점은 중등도의 위험 그 리고 58 100점은 최대의 위험으로 구분되어 점수가 높을 수록 낙상 위험이 높음을 의미한다.

\subsection{Procedure}

본 실험에 착수하기 전에 복부압박벨트(Corfit belt, Core products international Inc., USA)를 착용하고 균형 측정 기의 8 개 측정동작을 정확하게 수행할 수 있도록 매일 1시 간씩 1 주일간 연습하였다(Figure 2). 복부압박벨트 착용으 로 복부 심부근육이 증가되는지 확인하기 위하여 $\mathrm{PBU}$ 를 복 부와 복부압박벨트 사이에 위치시키고, 압력수치는 40 70 $\mathrm{mmHg}$ 에서 유지되도록 하고(Hodges, 2003), $7.5 \mathrm{MHz}$ 직 선형 도자(linear transducer)의 초음파(Logiq 200, 삼성 $-\mathrm{GE}$ 의료기., 대한민국)를 한발 서기 자세에서 12 번째 늑 골과 장골능(iliac crest) 가운데 지점에 횡축(transversely) 으로 위치시켜 심부 복부근육의 두께를 관찰하였다. 복부압 박벨트 착용으로 인하여 복횡근의 두께가 휴식 시의 두께보 다 증가되는 것을 확인하였고, 이를 수행하지 못할 경우 다 시 실시하였다. 균형 측정기를 사용한 본 실험에서는 $\mathrm{PBU}$ 와 초음파 도자를 제거하고 복부압박벨트만 착용하고 한발 서기 자세에서 실시하였다. 총 3 회 측정 후 평균값을 사용하 였다.

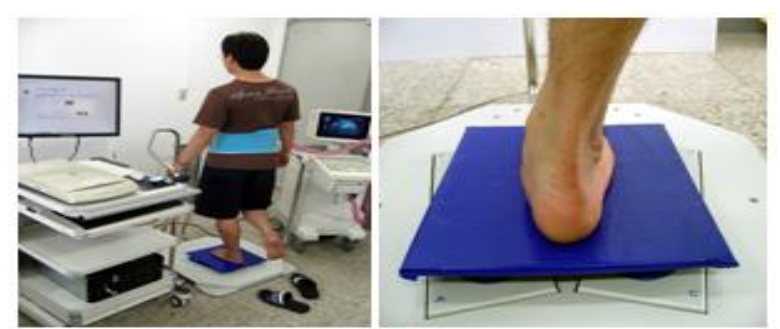

Figure 2. Abdominal-compression belt in one leg standing

Left: abdominal-compression belt Right: one leg standing

\subsection{Reliability test}

한발 서기용 발판에 대한 균형 측정기의 신뢰도는 4 명이 대상자 6명을 상대로 낙상 지수를 측정한 값에 대하여 급간 내 상관계수(intraclass correlation coefficent; ICC)를 계 산하였다. ICC $(2,1)$ 은 이차원 무작위형 (two-way random model) 과 절대동의 (absolute agreement)를 사용하였고, $\operatorname{ICC}(3,1)$ 은 이차원 혼합형 (two-way mixed model) 과 일 치(consistency)로 계산하였다.

\subsection{Data collection}

모든 측정 항목은 평균과 표준편차를 구하였다. 연구대상 자의 연령, 신장 및 체중으로 구성된 일반적 특성과 복부압 
박벨트 착용 유무에 따른 실험군과 대조군을 비교하기 위하 여 독립 $\mathrm{t}$-검정 (independent $\mathrm{t}$-test)을 사용하였다.

한발 서기용 발판에 대한 균형 측정기의 신뢰도를 측정하 기 위하여 낙상 지수 결과값을 이용하여 ICC를 계산하였다. 수집된 자료는 통계 프로그램 SPSS ver. 12.0을 사용하였 으며, 통계적 유의수준은 $p<.05$ 수준에서 결정하였다.

\section{Results}

\subsection{General stability index}

8가지 자세에서 복부압박벨트 착용 유무에 따른 실험군과 대조군의 일반적인 안정성 측정값들은 Table 2에 제시되 었다. 실험군과 대조군 사이에 $\mathrm{NO}, \mathrm{NC}, \mathrm{PO}, \mathrm{PC}, \mathrm{HR}, \mathrm{HL}$, $\mathrm{HB}$ 및 $\mathrm{HF}$ 는 모두 유의하였다 $(p<.05)$.

Table 2. GST results of application of the abdominal-compression belt

\begin{tabular}{c|c|c|c|c}
\hline Posture & Experimental & Control & $\mathrm{t}$ & $p$ \\
\hline $\mathrm{NO}$ & $2.90 \pm 17.73$ & $32.29 \pm 9.11$ & -2.162 & .037 \\
\hline $\mathrm{NC}$ & $19.80 \pm 45.21$ & $22.44 \pm 20.37$ & -2.954 & .005 \\
\hline $\mathrm{PO}$ & $25.46 \pm 10.07$ & $34.74 \pm 11.43$ & -2.723 & .010 \\
\hline $\mathrm{PC}$ & $28.10 \pm 15.17$ & $40.82 \pm 18.48$ & -2.372 & .023 \\
\hline $\mathrm{HR}$ & $19.67 \pm 8.28$ & $44.67 \pm 19.58$ & -5.260 & .000 \\
\hline $\mathrm{HL}$ & $20.76 \pm 9.56$ & $42.37 \pm 15.63$ & -5.274 & .000 \\
\hline $\mathrm{HB}$ & $23.70 \pm 11.87$ & $43.96 \pm 20.78$ & -3.787 & .001 \\
\hline $\mathrm{HF}$ & $21.68 \pm 10.74$ & $36.16 \pm 17.44$ & -3.162 & .003 \\
\hline
\end{tabular}

\subsection{Fourier harmony index}

8가지 자세에서 복부압박벨트 착용 유무에 따른 실험군과 대조군의 퓨리에 지수 측정값들은 Table 3 에 제시되었다. 실험군과 대조군 사이에 $\mathrm{HB}$ 와 $\mathrm{HF}$ 는 유의하였고 $(p<.05)$, $\mathrm{NO}, \mathrm{NC}, \mathrm{PO}, \mathrm{PC}, \mathrm{HR}$ 및 $\mathrm{HL}$ 는 유의하지 않았다 $(p>.05)$.

\subsection{Weight distribution index}

8가지 자세에서 복부압박벨트 착용 유무에 따른 실험군과 대조군의 WDI 측정값들은 Table 4에 제시되었다. 실험군과 대조군 사이에 $\mathrm{NO}, \mathrm{NC}, \mathrm{PO}, \mathrm{PC}, \mathrm{HR}, \mathrm{HL}, \mathrm{HB}$ 및 $\mathrm{HF}$ 는 모 두 유의하지 않았다 $(p>.05)$.
Table 3. FHI results of application of the abdominal-compression belt

\begin{tabular}{c|c|c|c|c}
\hline Posture & Experimental & Control & $\mathrm{t}$ & $p$ \\
\hline $\mathrm{NO}$ & $.87 \pm .09$ & $.81 \pm .11$ & 1.753 & .088 \\
\hline $\mathrm{NC}$ & $.86 \pm .13$ & $.81 \pm .15$ & 1.112 & .273 \\
\hline $\mathrm{PO}$ & $.91 \pm .05$ & $.88 \pm .10$ & 1.000 & .323 \\
\hline $\mathrm{PC}$ & $.88 \pm .13$ & $.86 \pm .11$ & .508 & .614 \\
\hline $\mathrm{HR}$ & $.86 \pm .12$ & $.83 \pm .16$ & .694 & .492 \\
\hline $\mathrm{HL}$ & $.81 \pm .16$ & $.79 \pm .15$ & .288 & .775 \\
\hline $\mathrm{HB}$ & $.88 \pm .09$ & $.73 \pm .23$ & 2.642 & .012 \\
\hline $\mathrm{HF}$ & $.82 \pm .18$ & $.70 \pm .18$ & 2.205 & .034 \\
\hline
\end{tabular}

Table 4. WDI results of application of the abdominal-compression belt

\begin{tabular}{c|c|c|r|c}
\hline Posture & Experimental & Control & $\mathrm{t}$ & $p$ \\
\hline $\mathrm{NO}$ & $5.37 \pm 2.86$ & $5.62 \pm 3.10$ & -.265 & .792 \\
\hline $\mathrm{NC}$ & $5.58 \pm 2.87$ & $5.36 \pm 3.19$ & .220 & .827 \\
\hline $\mathrm{PO}$ & $6.99 \pm 2.73$ & $5.60 \pm 3.05$ & 1.516 & .138 \\
\hline $\mathrm{PC}$ & $7.61 \pm 3.65$ & $7.09 \pm 4.40$ & .409 & .685 \\
\hline $\mathrm{HR}$ & $6.97 \pm 3.34$ & $5.91 \pm 3.73$ & .949 & .349 \\
\hline $\mathrm{HL}$ & $6.40 \pm 2.77$ & $6.34 \pm 4.02$ & .058 & .954 \\
\hline $\mathrm{HB}$ & $6.90 \pm 3.59$ & $6.61 \pm 3.74$ & .252 & .802 \\
\hline $\mathrm{HF}$ & $5.80 \pm 3.11$ & $7.43 \pm 3.99$ & -1.434 & .160 \\
\hline
\end{tabular}

\subsection{Fall index}

복부압박벨트 착용 유무에 따른 실험군과 대조군의 $\mathrm{FI}$ 측 정값은 Table 5 에 제시되었다. 실험군과 대조군 사이에 FI 는 유의하였다 $(p<.05)$.

Table 5. FI results of application of the abdominal-compression belt

\begin{tabular}{c|c|c|c}
\hline Experimental & Control & $\mathrm{t}$ & $p$ \\
\hline $53.40 \pm 18.01$ & $88.00 \pm 13.86$ & -6.810 & .000 \\
\hline
\end{tabular}

\subsection{Reliability}

한발 서기 자세용 발판을 이용한 균형 측정기에 대한 $\operatorname{ICC}(2,1)$ 은 .799, 95\% 신뢰구간은 .484 .964였으며, ICC $(3,1)$ 은 .777, $95 \%$ 신뢰구간은 .442 .960이였다. 


\section{Discussion}

균형조절은 산업체 근로자의 기능적인 일상생활동작 능력 에 필수적인 요소로, 이를 개선시키기 위한 운동방법들은 많은 연구들에 의해서 발표되고 있다. 본 연구에서는 균형 조절에 필요한 신경근골격계의 운동실행력에 초점을 두고 (Kisner and Colby, 2007), 최근 많은 관심을 받고 있는 척추 안정화 운동에 근거하여 동적인 상태에서도 지속적으 로 적용 가능한 복부압박벨트가 균형능력에 미치는 영향을 알아보고자 하였다. 대부분의 기능적 동작은 동적인 상태에 서 이루어짐에도 불구하고, 척추 안정화 운동과 관련된 대부 분의 연구는 정적인 상태에서 실시되는 방법과 측정들이 보 고되고 있다(Akuthota and Nadler, 2004; Cynn, 2010; Hodges, 2003). 복부압박벨트는 정적인 척추 안정화 운동 의 단점을 보완하여 지속적으로 적용이 가능하며, 근골격계 질환자에게 수동적으로 척추 안정화 효과를 기대할 수 있다. 따라서 작업 중인 산업체 근로자의 균형능력에 도움이 될 것 으로 사료되며, 이와 관련된 능력을 구체적으로 알아보고자 하였다.

균형능력을 평가하는 도구는 버그균형검사와 일어서 걷기 검사(Timed up and go test) 와 같은 주관적인 평가방법들을 대부분이다(Bogle et al., 1996; Horak et al., 2009). 그러나 본 연구에서는 기립 상태에서 머리 위치에 따른 다양한 자세 에서 균형능력을 객관적으로 측정하는 균형 측정기를 사용 하였다. 또한, 정상인을 대상으로 한 사전 연구(pilot study) 에서 양측발로 서있는 자세에서는 천장 효과(ceiling effect) 로 인하여 실험군과 대조군의 균형능력 차이를 발견할 수 없었기 때문에 한발 서기 자세에서 균형능력을 측정하였다. 이를 측정하기 위하여 균형 측정기의 4 개 발판에 적합하게 고안된 한발 서기용 목판을 제작하였다. 이러한 한발 서기 자세는 다양한 근로 환경에서 균형능력을 측정하기에 더 적 합한 것으로 사료되며, 정적인 상태에서 주로 실시되는 균형 측정의 단점을 보완하였다고 볼 수 있다.

척추 안정화 운동과 관련된 연구는 요통 환자를 대상으로 일정한 시간 동안 심부 복부근육을 강화시킴으로써 통증 및 기능 향상과 연계된 것이 대부분이다. 그러나 다양한 산업체 근로 환경에서 균형능력은 동적인 상태에서 다양하게 요구 되며, 일상생활동작 중에 수동적으로 지속시키기 위한 장비 는 부족한 실정이다. 이러한 근골격계 질환 예방을 위해서 복부압박벨트는 산업체 작업현장에서 유용하게 적용될 수 있을 것으로 사료된다. Park 등 (2010)은 골반주위의 압박 벨트 착용이 요방형근과 다열근과 같은 심부 복부근육을 강화시켜 고관절 외전에 도움을 준다고 하였고, Ratliffe 등 (1987)은 무게감 있는 압박벨트 착용이 정상인의 자세동요
에 효과적이라고 하였고, Liaw 등(2009)은 척추에 압력을 제공하는 보조기 착용이 척추압박골절에 의한 골다공증 환 자의 균형능력에 효과적이라고 하였다.

본 연구에서는 정확한 척추 안정화 효과를 훈련시키기 위 하여 초음파 영상을 사용하였다. 초음파 영상은 대부분 눕거 나(supine) 엎드린(prone) 정적인 자세에서 측정한다. 그러 나 본 연구에서는 서 있는 자세에서 탄력밴드와 고정 테입을 사용하여 초음파 도자를 복부표면에 고정시켰다. 복부압박벨 트에 의한 심부 복부근육의 변화를 관찰하기 위하여 $\mathrm{PBU}$ 와 초음파 영상을 동시에 사용하여 적절한 복부압력과 심부근 육의 두께가 유지되도록 교육 후 균형능력을 측정하였다. 이 러한 서기 자세에서의 초음파 측정방법은 트레드밀 걷기 및 달리기 자세에서 심부 복부근육의 두께를 실시간으로 측정 하기 위하여 초음파를 사용한 Bunce 등(2004)의 방법과도 유사하다. 초음파 측정 자료는 제시하지 못하였지만, 복부압 박벨트에 의한 정량적인 복부내압을 유지하기 위하여 실험 의 객관성을 높이기 위하여 초음파와 $\mathrm{PBU}$ 를 부가적으로 사 용하였다.

GST는 전반적인 균형능력을 의미하는 것으로 점수가 낮 을수록 균형능력 향상을 의미한다. 실험군에서 안정성 지수 가 더 작은 결과는 복부압박벨트 착용이 전반적인 균형능력 향상에 긍정적임을 나타낸다. 이러한 결과는 복부압박벨트 착용이 척추를 안정화시키고, 복부내압을 상승시킴으로써 전 반적인 균형능력에 도움을 준 것으로 사료된다. Cynn(2010) 은 한발 서기 자세에서 척추 안정화를 위한 요추부 근육의 동시수축이 자세조절 능력을 향상시킨다고 하였고, Damen 등 (2001)은 골반주위의 압박벨트 착용이 복부압력을 증가 시켜 천장관절을 안정화시킴으로써 균형능력에 도움을 준다 고 발표하였다.

$\mathrm{FHI}$ 는 실험군에서 $\mathrm{HB}$ 와 $\mathrm{HF}$ 만 유의한 차이를 보였다. $\mathrm{FHI}$ 는 시각과 전정기관이 통합되어 위치감각(position sense) 이 뇌의 자세유지기능 담당 부위에 전달되고, 이를 반영하는 지수로(Prasansuk et al., 2004), 머리 위치가 크게 동요될 수 있는 두 가지 자세에서 복부압박벨트 착용이 효과적으로 작용한 것으로 사료된다. $\mathrm{FHI}$ 는 저주파 $(1 \mathrm{~Hz}$ 이하)에서 고 주파 $(.5 \mathrm{~Hz}$ 이상)로 나누어 구분하기도 하지만 본 연구에서 는 값을 통합하여 계산하였으며, 이러한 방법은 $\operatorname{Sim}$ 등 (2009)의 선행연구에서도 동일하게 사용되었다. 본 연구에 서 전반적으로 $\mathrm{FHI}$ 가 낮게 측정된 이유는 양측발로 측정한 결과값이 아닌, 한발 서기 자세에서 균형능력을 측정하였기 때문인 것으로 고려된다.

$\mathrm{WDI}$ 는 4 개의 발판에 체중을 균등하게 분산시키는 능력으 로써, 8개 항목 모두에서 유의하지 않게 나타났다. 이러한 이 유는 복부압박벨트를 착용함으로써 척추 안정화 작용에는 효과적이였으나, 한발 서기 자세에서 한발에 균형을 적절하 
게 분산시키지 못한 것으로 고려된다. 균형조절을 위해서는 체간의 안정성뿐만 아니라 적절한 유연성도 조절되어야 하 지만(Kisner and Colby, 2007), 4 개의 발판 위에서 1 개의 발판으로 한발 서기 자세를 측정하였기 때문으로 사료된다.

$\mathrm{FI}$ 는 낙상 위험률을 나타내는 결과로써, 복부압박벨트 착 용이 낙상 예방에 효과적인 것으로 나타났다. 이는 노인 및 환자를 대상으로 실시한 척추 안정화 운동이 낙상 예방에 도 움을 준다고 발표한 선행연구들과도 일치하였다(Akuthota and Nadler, 2004; Hodges, 2003). 균형능력이 감소된 사 람은 낙상을 자주 경험하게 되며 (Kisner and Colby, 2007), 낙상 예방은 산업체 근로자들의 산업재해 위험요인으로 중요 하게 고려되어야 한다. 그러나 $\operatorname{Sim}$ 등(2009)과 Grüneberg 등(2004)은 연성 척추보조기 착용이 균형능력을 감소시킨 다고 발표하였다. 이러한 이유는 심부 복부근육을 선택적으 로 강화시키는 복부압박밴드와 다르게 연성 척추보조기는 척추 전체의 움직임을 제한시킴으로써 균형조절에 필요한 유연성이나 신경근골격계 시스템의 다른 문제를 야기시킨 것으로 보인다.

본 연구는 소수의 정상인을 대상으로 일시적인 효과를 측 정하였고, 균형조절 시에 사용되는 대상자의 운동 형상학적 자세는 분석하지 못하였다. 따라서 본 연구의 결과를 모든 정상인의 균형능력에 일반화시키기에는 제한점이 따르며, 장 기적인 효과를 판단하기는 무리가 따를 것이다. 추후 연구에 서는 많은 대상자에게 복부압박벨트를 장기적으로 착용하여 운동 형상학적인 분석과 함께 알아보아야 할 것이다.

\section{Conclusion}

한발 서기 자세는 균형, 보행 및 계단 오르기 등과 같은 작 업 환경에 선행되어야 하는 기본적인 기능동작으로(Kisner and Colby, 2007; Oude Hengel et al., 2010) 정상인의 균 형능력을 측정하기 위하여 본 연구에서 사용하였다. 복부압 박벨트는 작업 중에 심부 복부근육을 지속적으로 강화시킴 으로써 근골격계 환자의 척추 안정화 효과를 수동적으로 적 용할 수 있을 것이다. 이러한 복부압박벨트의 장점과 유용성 에도 불구하고 산업체 현장에서는 적용의 단순성으로 인하 여 간과되고 있는 것이 사실이다. 따라서 본 연구는 복부압 박벨트를 착용하고 한발 서기 자세에서 균형능력에 미치는 영향을 객관적인 균형 측정기를 이용하여 구체적으로 알아 보았다. 그 결과, 전반적인 균형능력과 낙상 예방에 긍정적 인 간편하고 유용한 보조도구임을 알 수 있었다.

\section{Acknowledgements}

This authors with to thank the subjects who took part in this study. No funding was supported for this work. Conflict of interest: None declared.

\section{References}

Akuthota, V. and Nadler, S. F., Core Strengthening. Archives of Physical Medicine and Rehabilitation, 85, 86-92, 2004.

Bogle Thorbahn, L. D. and Newton, R. A., Use of the Berg Balance Test to predict falls in elderly persons, Physical Therapy, 76(6), 576-583, 1996.

Bunce, S. M., Hough, A. D. and Moore, A. P., Measurement of abdominal muscle thickness using M-mode ultrasound imaging during functional activities, Manual Therapy, 9(1), 41-44, 2004.

Cynn, H. S., Oh, J. S., Kwon, O. Y. and Yi, C. H. Effects of lumbar stabilization using a pressure biofeedback unit on muscle activity and lateral pelvic tilt during hip abduction in sidelying, Archives of Physical Medicine and Rehabilitation, 87(11), 1454-1458, 2006.

Cynn, H. S., Effect of lumbar stabilization on the trunk and lower limb muscle activity and velocity of the center of pressure during single leg standing, Physical Therapy Korea, 17(4), 1-8, 2010.

Damen, L., Buyruk, H. M., Güler-Uysal, F., Lotgering, F. K., Snijders, C. J. and Stam, H. J., Pelvic pain during pregnancy is associated with asymmetric laxity of the sacroiliac joints, Acta obstetricia et gynecologica Scandinavica, 80(11), 1019-1024, 2001.

Grüneberg, C., Bloem, B. R., Honegger, F. and Allum, J. H., The influence of artificially increased hip and trunk stiffness on balance control in man, Experimental brain research, 157(4), 472-485, 2004.

Hodges, P. W., Core stability exercise in chronic low back pain, The Orthopedic clinics of North America, 34(2), 245-254, 2003.

Horak, F. B., Wrisley, D. M. and Frank, J., The Balance Evaluation Systems Test(BESTest) to differentiate balance deficits, Physical Therapy, 89(5), 484-498, 2009.

Kim, C. R., Chun, M. H. and Lee, G. A., Assessments of balance control using tetra-ataxiametric posturography, Journal of Korean Academy of Rehabilitation Medicine, 33(4), 429-435, 2009.

Kim, S. Y. and Baek, I. H., Effects of Transversus Abdominal Muscle Stabilization Exercise to Spinal Segment Motion on Trunk FlexionExtension, Physical Therapy Korea, 10(1), 63-76, 2003.

Kisner, C. and Colby, L. A., Therapeutic Exercise: Foundation and techniques, 5th ed, Philadelphia, FA Davis, 2007.

Kohen-Raz, R., Application of tetra-ataxiametric posturography in clinical and developmental diagnosis, Perceptual and motor skills, 73(2), 635 $-656,1991$.

Lee, N. G., Effects of the abdominal drawing-in maneuver(ADIM) on core and postural stability in adults with core instability, Yonsei Graduate 
University, 2010.

Liaw, M. Y., Chen, C. L., Chen, J. F., Tang, F. T., Wong, A. M. and Ho, H. H., Effects of Knight-Taylor brace on balance performance in osteoporotic patients with vertebral compression fracture, Journal of back and musculoskeletal rehabilitation, 22(2), 75-81, 2009.

Mens, J. M., Damen, L., Snijders, C. J. and Stam, H. J., The mechanical effect of a pelvic belt in patients with pregnancy-related pelvic pain, Clinical biomechanics, 21(2), 122-127, 2006.

Oude Hengel, K. M., Joling, C. I., Proper, K. I., Blatter, B. M. and Bongers, P. M., A worksite prevention program for construction workers: design of a randomized controlled trial, BMC public health, 14(10), 336, 2010.

Park, K. M., Kim, S. Y. and Oh, D. W., Effects of the pelvic compression belt on gluteus medius, quadratus lumborum, and lumbar multifidus activities during side-lying hip abduction. Journal of electromyography and kinesiology, 20(6), 1141-1145, 2010.

Pel, J. J., Spoor, C. W., Goossens, R. H. and Pool-Goudzwaard, A. L., Biomechanical model study of pelvic belt influence on muscle and ligament forces, Journal of biomechanics, 41(9), 1878-1884, 2008.

Prasansuk, S., Siriyananda, C., Nakorn, A. N., Atipas, S. and Chongvisal, S., Balance disorders in the elderly and the benefit of balance exercise. Journal of the Medical Association Thailand, 87(10), 1225-1233, 2004.

Ratliffe, K. T., Alba, B. M., Hallum, A. and Jewell, M. J., Effects of approximation on postural sway in healthy subjects, Physical Therapy, 67(4), 502-506, 1987.

Sim, N. E., Lee, M. J., Cho, I. R. and Chang, M. Y., The change of balance according to the wearing of flexible spine orthosis, The Journal of Korean Society of Assistive Technology, 1(1), 29-40, 2009.

Willson, J. D., Dougherty, C. P., Ireland, M. L. and Davis, I. M., Core stability and its relationship to lower extremity function and injury, The Journal of the American Academy of Orthopaedic Surgeons, 13(5), 316-325, 2005.

\section{Author listings}

Ki -Yeon Chang: kiyeon@lion.woosong.ac.kr

Highest degree: $\mathrm{PhD}$, Department of Occupational Therapy, Yonsei University

Position title: Associate Professor, Department of Occupational Therapy, the University of Woosong

Areas of interest: Industrial medicine

Seung-Chul Chon: keyjune@konyang.ac.kr

Highest degree: PhD, Department of Physical Therapy, Yonsei University Position title: Full-time lecturer, Department of Physical Therapy, the University of Konyang

Areas of interest: Human engineering, Musculoskeletal disorders

Date Received : 2011-03-17

Date Revised :2012-03-06

Date Accepted : 2012-03-06 